\title{
Supporting Partner Selection for Virtual Enterprises
}

\author{
Jens Dahl Pedersen \\ Technical University of Denmark, Denmark \\ Em: jdp@ipt.dtu.dk
}

Roelof J. van den Berg

Baan Development, The Netherlands

Em: rvdberg@baan.nl

Keywords Virtual enterprise, partner selection, partner qualification, competencies

\begin{abstract}
This paper discusses partner selection for virtual enterprises. It provides a framework to define the notion of the virtual enterprise. It also defines the concepts resource, capabilities and competence and explains that two types of competence are essential to operate successfully in a virtual enterprise: functional competence and alliance competence. It discusses how they can be described and assessed.
\end{abstract}

\section{INTRODUCTION}

Current initiatives on business-to-business e-commerce tend to emphasise strictly technological requirements. While technological integration of distributed information systems is a key prerequisite for VEs, partner selection is another considerable obstacle. Evidence indicates that successful alliances rarely come to existence by chance, and that a main reason pitfalls often is poor partner selection resulting in mismatch between partners or unqualified partners for the particular job [5,7,13]. At the same time, the required agile formation of VEs leaves little room to sound out well-qualified and trustworthy partners. This is often a matter of years in project industries today. Based on a theoretical framework for VE concepts, this paper will define key concepts as well as highlight current challenges to successful partner selection for VEs. 


\section{THE VIRTUAL ENTERPRISE FRAMEWORK}

A VE can shortly be described as a customer solution delivery system created by a temporary and re-configurable aggregation of core competencies [16]. A VE is thus an alliance, where individual enterprises join competencies in order to establish a customer oriented value system. This value system is carefully configured to meet a specific customer demand and when the demand has been fulfilled, the VE is dissolved.

The concept of VEs is captured and formalised by the framework for VE engineering and integration as is illustrated in figure $1[9,15,16]$. The framework illustrates that VEs originate in a network of co-operating organisations. The network represents a pre-established basis of competence carriers, for preparing and setting up VEs. In practice, it is not always easy to see who is within a network and who is not, because the closeness of the partnerships within the network varies. The network can create VEs in its operational phase and, correspondingly, a VE can create product(s) or service(s) in its operational phase.

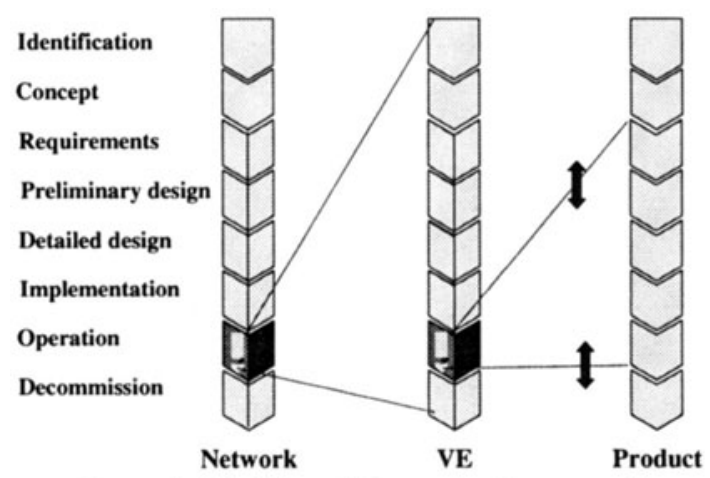

Figure 1: The Virtual Enterprise Framework

\section{COMPETENCE DEFINED}

The notions of resources, capabilities and competencies have gained considerable attention from scholars of strategic management research as they attempt to explain why companies differ in organisational performance. Particularly, what has become known as the resource-based view of the firm is dedicated to research on this question. The three concepts are however subjects of a rich variety of different definitions and often used highly synonymously.

For this paper a distinction between resources and capabilities is made based on the definitions set forth by Amit and Schoemaker. They define 
resources as "stocks of available factors that are owned or controlled by the company" [1]. Resources encompass both tangible and intangible assets [17] and can basically be categorised into three types: physical capital resources, human capital resources and organisational capital resources [2]. Physical capital resources include the physical technology, facilities, equipment, and materials. Human capital resources include education, experience, judgement, intelligence, and relationships. Organisational capital resources include formal reporting structure, formal and informal planning, controlling and co-ordinating systems as well as informal relationships [2].

In the view of Amit and Shoemaker capabilities refer to a company's capacity, or ability, to deploy resources. Capabilities are information- and knowledge-based processes deploying resources in an often co-ordinated way to effect a desired outcome as for instance products, services, organisational behaviour, trust and the like. Like resources, capabilities can be both tangible and intangible, but they are in essence limited to the information- and knowledge handling of human capital resources [1].

Competencies are complementarily a subset of resources and capabilities with the potential to lead to competitive advantages. The above characteristics of resources and capabilities also apply to competencies, but to constitute a competence, the resources and capabilities must meet the following criteria $[2,10]$ :

a) they must promote company efficiency and effectiveness and be perceived as valuable by the market and environment;

b) they should not be readily available at competitors;

c) they should be difficult to acquire for competitors;

d) they should not have strategically equivalent abundant substitutes

Note that a competence here is defined relative to competencies of other companies. Besides, a competence should not be confused with a specific product or service, rather a competence spans the ability to create several products or services.

\section{COMPETENCE MODELLING}

To create a successful VE it is necessary that its potential members have a thorough understanding of each other's competencies. For this purpose each one of them should be able to demonstrate the viability of its competencies to the others. In addition it should be able to show how its competencies add value to the planned VE by complementing those of others. Thus, it is not sufficient to have an intra-firm focus on competencies. Companies should be willing and able to look beyond their own boundaries as well. 
Modelling of competencies should in this respect be perceived as a way for companies to qualify themselves to participate in VEs. Modelling competencies has many advantages, both intra- and inter-organisationally. Here we want to emphasise that the models facilitate much better communication about competencies with external parties, for the above mentioned reasons. This is especially true when some kind of standardised technique and format is used. It is not unlikely that eventually dedicated agencies will arise, which assist enterprises in modelling their competencies and also assess their suitability for a certain network or a particular virtual enterprise. See [3] for a description of the state of the art in audits for ecommerce and [4] for an outline of what is needed in this respect. To participate in a VE, companies should possess two types of competencies:

\section{- functional competence}

This is a competence related to the product life cycle, therefore supporting the creation of the customer solution.

- alliance competence

This is competence related to the VE life cycle, representing the ability

of a partner to enter into and participate in VEs.

These two types of competencies are implicitly recognised by $[6,12]$ and will be discussed subsequently.

\subsection{Functional Competence}

Functional competencies are the competencies that partners bring to a VE to form an operational entity that can carry out the phases of the product life cycle, cf. figure 1. Definition and modelling of competencies are key issues for describing, communicating and justifying competencies offered for VEs. Very few companies have, today, an accurate and living model of their business processes let alone their wider capabilities and competencies. To facilitate an agile formation of VEs, allow a somewhat objective comparison of partners, and reduce misperceptions and dishonesty between partners, systematic and standardised methods for defining and modelling of competencies are needed [6]. Unfortunately, the competence literature rooted in the resource based view of the firm does not at the current state offer operational support for description of competencies. In an initial attempt, the dimensions mentioned below could be used relevant for description of functional competencies.

A) Solution addressed by the competence

This is an overall description of what market need the competence addresses.

B) Supporting resources and capabilities 
This includes a more detailed model of the application sphere, constraints and uniqueness of the competence, which is useful for evaluation of the competence against more specific project requirements. It should indicate how the competence results in specific products or services, e.g. by describing basic assumptions, paradigms, theories, or methods.

C) Interfaces

It should be described what input, typically in terms of information and knowledge, the competence requires as well as what output it is expected to deliver. This should clarify dependencies and make expectations explicit.

D) Agility

This should describe how agile the resources and capabilities can operate (i.e. internal agility) as well as the degree of agility the competencies bring to the VE (i.e. external agility) [6].

E) Sensitivity

A description of sensitivity should describe how well rooted the competence is in the organisation and hereby how resistant it is to especially resignation of key employees.

\section{F) Additional measures}

Finally a competence model should be accompanied by a set of additional measures including measures for quality, capacity, and financial performance.

Each of the above dimensions needs to be complemented with specific metrics to make them sufficiently descriptive, measurable, and thus fully operational. Even though not all aspects of a competence can be modelled due to the inherent complexity and presence of tacit knowledge, it is possible to get a part of the way.

\subsection{Alliance Competence}

Possession of functional competencies is not sufficient to qualify for a VE. A VE is in essence a partnership between autonomous companies, which implies a high degree of interaction and integration to achieve common objectives. Therefore, companies must also possess ability to enter into and participate in VEs, or in other words, they must possess alliance competence. The notion of alliance competence is introduced by Spekman and MacAvoy, who characterises it as "partly a function of individual skills and capabilities and firm-level attributes that enhance, encourage, and support alliance-like thinking and behavior throughout the firm" [12]. Two main elements of an alliance competence are ability to manage and implement alliances and ability to display alliance spirit and behaviour. 
An ability to manage and implement alliances includes thus both the formation, operation, and decommission of the VE while considering the product life cycle and starting from the partners in the network [15]. Naturally, the scope of resources and capabilities comprising an ability to manage and implement alliances should depend on the particular role(s) a company expects to have in VEs. For a design office or a production facility with a more secondary role in managing and implementing the VE this scope can be more limited than for the main contractor or an agent of competencies.

An ability to manage and implement alliances should preferably qualify a company to enter into and operate in VEs in an agile, plug and play fashion. It is possible to reuse and enhance the company's existing alliance knowledge and realise a certain degree of preparation for participation in VEs. Such preparation could be achieved by reference models for the VE formation process including partner selection criteria, standard contracts, models for risk and profit sharing, and ways of co-operating and communicating. When these elements are combined by powerful technology for process configuration in a virtual enterprise, the alliance competence increases significantly. This directly addresses the need for flexibility to partner with a variety of companies. Additional elements of an ability to manage and implement alliances are the ability to certify potential unqualified partners, acquire new qualifications, and to manage changes across the entire set of partners.

Ability to display alliance spirit and behaviour is largely a matter of organisational behaviour and relationship management. According to Spekman and MacAvoy alliance spirit builds on an atmosphere of flexibility, commitment to mutuality, sense of solidarity, and preference for harmony [11]. It should be stressed that displaying alliance spirit and behaviour relies on human skills and personal match between people.

Partners in VEs should display tolerant and respectful behaviour and in the common interest of the VE, thus avoiding opportunistic and power based behaviour. Partners should besides be willing to share information, respect IPR and trusted information, be open for teaching as well as learning, respect cultural differences, and understand motives of partners. Although alliance spirit builds very much on characteristics that are intrinsic to a potential partner, an atmosphere of trust in a VE is always the result of interaction between several partners. Business logic precludes an attitude of complete naivety in partnering and sharing, as a viable business strategy. Trust has to grow on joint successes [11]. 


\section{CONCLUSION}

Work on electronic business tends to emphasise the first half of the concept. It almost completely ignores that age-old challenges associated with commercial projects have to be addressed as well to truly realise a "new economy". One of these challenges is the selection of business partners. In the virtual enterprise this has to be done much faster than what is common today.

At this moment few companies are prepared to rapidly gear up for participation in a specific virtual enterprise. In case they have a clear comprehension of their competencies, it is used for internal purposes only. Techniques to systematically describe and communicate competencies need to be developed, as well as methods to objectively assess them.

Because these functions will easily distract most enterprises from their core business, it is not unlikely that they eventually will be covered by dedicated intermediaries. This applies to both functional and alliance competence. From this perspective it is likely that maturity models for VE partnering will emerge over time hand in hand with third party certification.

\section{REFERENCES}

[1] Amit R., Schoemaker P.J.H. (1993). Strategic Assets and Organizational Rent, Strategic Management Journal, 14, 33-46

[2] Barney J. (1991). Firm Resources and Sustained Competitive Advantage, Journal of Management, 17, 99-120

[3] Berg, R.J. van den, and Lieshout, van, J.M. (1999). Eliminating Hurdles to Trust in Ecommerce, in Global Production Management, K. Mertens, O. Krause and B. Schallock (eds.), Kluwer, pp. 522-529.

[4] Berg, Van den, R. J. and Tølle, M. (2000). Assessing Ability to Execute in Virtual Enterprises,

[5] Brouthers K.D., Brouthers L.E., Wilkinson T.J. (1995). Strategic Alliances: Choose Your Partners, Long Range Planning, 28, 18-25

[6] Goranson H. T. (1999). The Agile Virtual Enterprise: Cases, Metrics, Tools, Quorum Books

[7] Medcof J.W., (1997). Why Do Many Alliances End in Divorce, Long Range Planning, 30, 718-732

[8] Prahalad C.K., Hamel G. (1990). The Core Competence of the Corporation, Harvard Business Review, 68, 79-91

[9] Pedersen J.D., Vesterager J., Tølle M. (2000). Application of a GERAM based Virtual Enterprise Framework - Results from IMS 950001/Esprit 26509, Proceedings of the $6^{\text {th }}$ International Conference on Concurrent Enterprising, Toulouse, 28-30 June 2000, 139143

[10] Peteraf M.A. (1993). The Cornerstone of Competitive Advantage: A Resource-based View, Strategic Management Journal, 14, 179-191 
[11] Sabherwal R. (1999). The Role of Trust in Outsourced IS Development Projects, Communications of the ACM, 42, 80-86

[12] Spekman R.E., Isabella L.A., MacAvoy T.C. (2000). Alliance Competence Maximizing the Value of Your Partnerships, John Wiley \& Sons

[13] Spekman R.E., Isabella L.A., MacAvoy T.C. (1996). Creating Strategic Alliances which Endure, Long Range Planning, 29, 346-357

[14] Talluri S., Baker R.C. (1996). A Quantitative Framework for Designing Efficient Business Process Alliances, IEMC, 656-661

[15] Tølle M., Vesterager J., Pedersen J. (2000). A Methodology for Virtual Enterprise Management - Results from IMS 95001/Esprit 26509 Globeman 21 project, Proceedings of the $6^{\text {th }}$ International Conference on Concurrent Enterprising, Toulouse, 28-30 June 2000, 119-129

[16] Vesterager J., Larsen L. B., Gobbi C. (1999). Architecture and methodology for creating virtual enterprises - results from Globeman 21, www.vtt.fi/aut/projects/gm21/demo/index 2. thml

[17] Wernerfelt B. (1984). A Resource-based View of the Firm, Strategic Management Journal, 5, 171-180 